\title{
Impacts of Microbial Growth on the Air Quality of the International Space Station \\ ${ }^{a}$ Ariel V. Macatangay, ${ }^{b}$ Rebekah J. Bruce
}

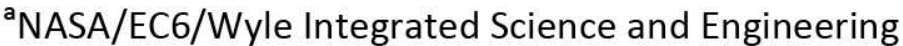 \\ ${ }^{\mathrm{b}} \mathrm{NASA} / \mathrm{SF} /$ Wyle Integrated Science and Engineering
}

An understanding of the various sources of non-methane volatile organic compounds (NMVOCs) is one facet to ensuring the habitability of crewed spacecraft. Even though the International Space Station (ISS) atmosphere is relatively well characterized in terms of what is in the atmosphere and approximately how much, linking the majority of these trace contaminants detected to their source is virtually impossible. Albeit a few of can be associated to a single source, the majority of these trace contaminants have their origins from multiple sources. On crewed spacecraft such as ISS, trace contaminants are broadly categorized as either coming from equipment, which includes systems and payloads, or from the metabolic processes of the crew members. Such widely encompassing categories clearly illustrate the difficulty in linking air contaminants to their source(s). It is well known that microbial growth in ISS can flourish if left unchecked. Although processes are in place to limit microbial growth, in reality, microbial growth has pervaded the habitable environment of ISS. This is simply a consequence of having crewed spacecraft, as humans are the largest contributor to the bioload. As with crew members, microbes also have metabolic processes which, in many ways, are comparable to human metabolism. As such, it can be expected that microbial growth can lead to the release of volatile organic compounds into the ISS atmosphere. Given a large enough microbial population, the impact to the air quality of ISS can be potentially large. A survey of the microbiology found in ISS will be presented as well as the possible types of volatile organic compounds that can result from such organisms. This will be correlated to the observations provided by ground-based analysis of ISS atmosphere samples.

\section{Introduction}

Air-quality data obtained from the International Space Station (ISS) provides much information regarding the maintenance of the cabin atmosphere aboard long-lived space habitats. Cabin air quality information reflects not only chemicals introduced into the cabin atmosphere, but also the day-to-day function and performance of the systems in the spacecraft and the crew tasks on-board. These factors combine in a synergistic manner to ultimately determine cabin air quality.

Submarines and tightly-built buildings are the closest analogs to manned spacecraft in terms of sealed atmospheres. The management of the quality of the interior atmosphere is paramount to the health and well-being of those who live and work in all three structures. All are designed to protect occupants from external environments and the interior atmosphere is subject to chemical infiltration. The source of chemical 
contaminants is typically attributed to material off-gassing, system-related chemicals, human or animal metabolism, and by different human activities. A simple way to deal with these atmospheric contaminants is to vent the interior atmosphere to fresh air, an option available to buildings and, to a great extent, submarines, but not necessarily available to manned spacecraft due to limited in-flight resources. Cabin air quality in manned spacecraft can only be managed with integrated hardware in conjunction with design specifications and both ground-based and flight-based operational rules and procedures. These are essentially designed to minimize the release of chemical contaminants into the cabin atmosphere and to provide a means to remove contaminants that do get into the cabin atmosphere.

\section{Trace Contaminant Control on ISS}

There are two, primary systems to control levels of trace contaminants on-board the ISS, the Trace Contaminant Control System (TCCS) in the U.S. Lab, Destiny, and the Micropurification Unit, БMП, in the Russian Service Module (SM), Zvezda.(Macatangay, et al, 2007) Even though either system is designed to handle ISS cabin atmospheric scrubbing independently with a crew of six, both are nominally operational. A second TCCS is currently located in Node 3 and is identical to the system in the U.S. Lab and can provide the same functionality. If maximum scrubbing capabilities are required, e.g., during an off-nominal situation, all three systems can be operated simultaneously.

The Russian БМП is comprised of four separate beds: a non-regenerable, activated charcoal pre-filter, two, regenerable activated charcoal filters, and an ambient temperature catalyst canister. High molecular weight contaminants are removed by the non-regenerable activated charcoal bed. Lower molecular weight contaminants are then removed by splitting the air flow into two equal streams and passing each stream through a regenerable, activated charcoal bed. The nominal flow rate through the БМП is $27 \mathrm{~m}^{3}$ /hour. Just prior to reintroduction into the cabin, the cabin air is passed through an ambient temperature catalyst canister to remove residual carbon monoxide and hydrogen.

The TCCS in the U.S. Lab (and Node 3) is comprised of three beds. Cabin atmosphere is drawn into the trace contaminant control system and initially passed through an activated charcoal bed (treated with $10 \%$ phosphoric acid by weight) to remove high molecular weight compounds and ammonia. Approximately $30 \%$ of the cabin air exiting the activated charcoal bed is then passed through a catalytic oxidizer assembly at a temperature of $400^{\circ} \mathrm{C}$ to remove contaminants that absorb poorly on the activated charcoal bed. Immediately downstream of the catalytic oxidizer assembly is a lithium hydroxide bed to neutralize acid gases that may form in the catalytic oxidizer assembly and to remove carbon dioxide generated from the complete oxidation of organic compounds. Prior to reintroduction into the cabin, the $30 \%$ catalytically oxidized process air is recombined with the $70 \%$ that bypassed the catalytic oxidizer stream. The amount bypassed is a function of the chemicals that served as the design drivers for the 
catalytic oxidizer bed and the residence time required for complete oxidation. The nominal flow rate through the U.S. TCCS is $15.3 \mathrm{~m}^{3} /$ hour. Although none of the beds are regenerable, orbital replacements for each bed can be launched. The recommended service intervals are estimated to be 4.5 years for the activated charcoal bed, 5 years for the catalytic oxidizer bed, and 3.5 years for the lithium hydroxide bed, depending on cabin atmosphere contaminant concentrations and any off-nominal events that may occur during the lifetime of the beds.

Although their primary function is not trace contaminant removal, other systems onboard the ISS can help lower trace contaminant concentrations. Carbon dioxide removal in the U.S. On-orbit Segment (USOS) of ISS is handled by the Carbon Dioxide Removal Assembly (CDRA) at a rate of approximately $34 \mathrm{~m}^{3} / \mathrm{hr}$. The primary CDRA is located in the U.S. Lab with a second, identical system located in Node 3 . Under nominal operations, the primary CDRA will function with the second CDRA serving as a backup system. The active removal components in the CDRA are two packed beds containing zeolite 5A molecular sieve. Zeolites are aluminosilicates noted for the acidity of their surfaces and highly consistent pore size resulting from a highly symmetric structure. System level testing has shown that CDRA is effective not only at removing carbon dioxide, but also in the removal of acetone at 33\% efficiency, methylene chloride at $50 \%$, methanol at $33 \%$ efficiency, m-xylene at $53 \%$ efficiency, and ammonia at $43 \%$ efficiency.

Removal of cabin atmosphere contaminants by the Common Cabin Air Assembly (CCAA) in the US Lab and by the SKV of the Russian Service Module operates by absorbing the contaminants into the humidity condensate. The humidity condensate is collected and processed by the Russian water processing system, SRV-K, and the U.S. processing system, Water Processing Assembly (WPA). SRV-K uses two-phase catalytic conversion of volatile organics in a filter reactor followed by a multi-filter unit (MFU) beds comprised of ion exchange, adsorption, and catalytic oxidation. The WPA uses a combination of ion-exchange and catalytic oxidation for water purification followed by iodination. Excessive contaminant concentrations can result in the break-through of contaminants through the catalytic bed, yielding non-potable water. Nevertheless, the concentration of relatively low-molecular weight, polar, water-soluble cabin contaminants can be effectively controlled with the humidity condensate.(Macatangay, et al, 2007)

\section{Chemical Constituents in Spacecraft Cabin Atmosphere}

Archival sampling provides a "snapshot" of the constituents that make up the cabin atmosphere. Obtained at regular intervals, these "snapshots" can be combined to provide insight into contaminant concentration trends over a period of time. This information is invaluable not only to system engineering, but also to toxicologists who limit risks to crew health by setting exposure limits to chemicals. Trends in contaminant 
concentration provide direct feedback regarding the performance of life support systems on-board spacecraft.

Archival samples of spacecraft cabin atmosphere can be obtained by several methods.(Perry, et al, 1997) Samples of the ISS cabin atmosphere are obtained using sorbent tubes and grab sample containers. Sorbent tubes are metal or glass tubes, typically packed with Tenax GC beads, a polymer based on 2, 6-diphenyl-p-phenylene oxide. As a volume of the cabin atmosphere is drawn into the tube by a hand-operated bellow, contaminants in the atmosphere are absorbed onto the Tenax beads. When returned from orbit, Tenax beads undergo thermal desorption and concentrated effluent analyzed by standard U.S. Environmental Protection Agency (EPA) methods. Grab-sample containers (GSCs) are 500-ml evacuated, stainless steel vessels with passivated interior walls. Prior to launch, each GSC is dosed with trace amounts of surrogate compounds to account for any bias introduced by handling, storage, and return of the sample container. Once in flight, a sample of the cabin atmosphere is obtained by opening the container to the cabin atmosphere and allowing the pressure inside the grab-sample container to equilibrate with the spacecraft cabin. As with sorbent tubes, ground analysis of GSC samples involves concentrating and analysis by EPA methods. The preparation of sorbent tubes and GSSCs and the analysis of their contents are rigorously documented and constantly inspected. The processes followed were governed by standard operating procedures and by safety, reliability, and quality assurance policies.

Complimentary information can be obtained by using both sorbent tubes and GSCs and together, provide a broad coverage of a very wide range of chemical contaminants. Highly volatile contaminants not readily trapped by sorbent tubes such as hydrogen, carbon monoxide, C1-C4 hydrocarbons, and halocarbons are more reliably sampled with GSCs, whereas sorbent tubes are best suited for polar and relatively heavy, non-polar organic contaminants. Also, sorbent tubes and GSCs are relatively simple ways to "record" transient events such as an inadvertent release of chemicals into the cabin or any other off-nominal event. Time-integrated samples during these times are of particular value in understanding contaminant dynamics aboard spacecraft.

Chemical contaminants in the spacecraft cabin atmospheres have been attributed to two basic sources-hardware and crew. Within the context of this discussion, hardware includes equipment and payload. Chemicals from hardware may come from system chemicals or off-gassing from materials used in the construction of the systems. Payloads can be further broken down to include equipment and experiments. Payload equipment, similar to systems, may have chemicals associated with their functionality, and experience off-gassing. Systems on-board spacecraft and payload equipment can be characterized as continuous sources of atmospheric contaminants. Continuous sources have long term emissions of chemical contaminants with relatively constant source strength. Chemicals associated with experiments brought on-board spacecraft can be characterized as discontinuous sources of atmosphere contaminants having 
short term emission of chemical contaminants with varying source strength. By and large, spacecraft systems and payload equipment are a greater source of cabin atmosphere contaminants than payload experiments. Hundreds of kilograms of system chemicals such as coolants may be present on-board spacecraft. Comparatively, chemicals associated with payload experiments are typically present in several gram quantities and are subject to multiple containment levels to prevent accidental release.

Although not necessarily considered a source of atmosphere contaminants when discussing indoor air quality on ground, the crew is a source of a diverse number of chemical contaminants. Human metabolism is the main source of ammonia, carbon monoxide, methane, hydrogen, several short chain carbonyl compounds, and alcohols on-board spacecraft and can be considered to be a continuous source of contaminant generation into the cabin atmosphere.(Perry, 1998) Contaminants from crew metabolism differ from contaminants generated by hardware in the sense that they cannot be regulated by ordinary means.

To a great extent, cabin atmospheric contaminants from hardware can be regulated by proper material selection, multiple containment levels, and design for minimum risk. Limiting contaminant concentrations by limiting the amount used on-board spacecraft can be very effective. Because of their potential negative impact on the Russian water processing system, SRV-K, the use on board ISS of water soluble volatile organic compounds such as alcohols, acetone, and glycols have been limited through a volatile usage agreement requirement. Items containing water soluble volatile organic compounds that can be introduced into the ISS cabin atmosphere in excess of a $1 \mathrm{~g} /$ day limit are subject to this agreement. Justification by the payload organization and rationale as to why a substitute cannot be used must be provided. This requirement impacts not only items brought to the ISS, but also the on-ground procedures used to prepare hardware for flight. Alcohol wipes (medical, maintenance, and housekeeping), contact lens cleaning fluid, and other crew hygiene products previously allowed onboard were now replaced with water-based, benzalkonium wipes or something similar. On the ground, alcohol-containing wipes used to remove fingerprints or any oils just prior to stowage for launch were also replaced with water-based, benzalkonium wipes within 5 days of final hatch closure to reduce introduction of residual alcohol into the cabin atmosphere. Since requirements like these cannot be levied against metabolic processes, crew metabolism will always be a constant source of cabin atmosphere contaminants on-board spacecraft.

The ISS cabin atmosphere is very dynamic, constantly responding to changes in crew activities, payloads, equipment, and constant scrubbing. The presence of inter-modular ventilation typically allows the assumption that the cabin atmosphere is well mixed between the various modules. Air quality data and crew observations have shown that this may not be a valid assumption. With the lack of gravity, natural convection is absent and diffusional mixing can be quite slow. It is well known that pockets of carbon dioxide can exist in areas within a single module. A simple blockage of air-intake vents 
with dust and debris have been shown to have a profound effect on the concentration dynamics of formaldehyde.

The chemicals found in the ISS atmosphere is categorized as one of two types of constituents - trace contaminants and major constituents. Major constituents are defined as oxygen, nitrogen, methane, hydrogen, water vapor, and carbon dioxide. Major constituent levels are monitored in real time by the Major Constituents Analyzer (MCA) in the atmosphere revitalization rack of the U.S. Lab, Compound Specific Analyzer - Oxygen (CSA-O2), and the Carbon Dioxide Monitoring Kit. As with TCCS and CDRA, a second, identical MCA is located in Node 3 and serves as a backup to the primary MCA in the U.S. Lab. A nominal picture of the constituents that make up the ISS cabin atmosphere can be seen in Figure 1. In this graph, octafluoropropane (Freon218) was removed due to off-nominal cabin atmosphere concentrations which resulted from a leak from the Russian thermal control system in 2001-2002 and in 2008. The high concentration of octafluoropropane artificially skews the nominal, on-orbit halocarbon concentrations and as such, octafluoropropane was excluded to give a more representative picture of the ISS cabin atmosphere constituents. Figure 2 illustrates the organic chemical groups that contribute to the total non-methane volatile organic compounds (NMVOCs). From the graph, alcohols are the major contributor to NMVOC levels. Driving this level of alcohols are ethanol, methanol, isopropanol, and n-butanol.

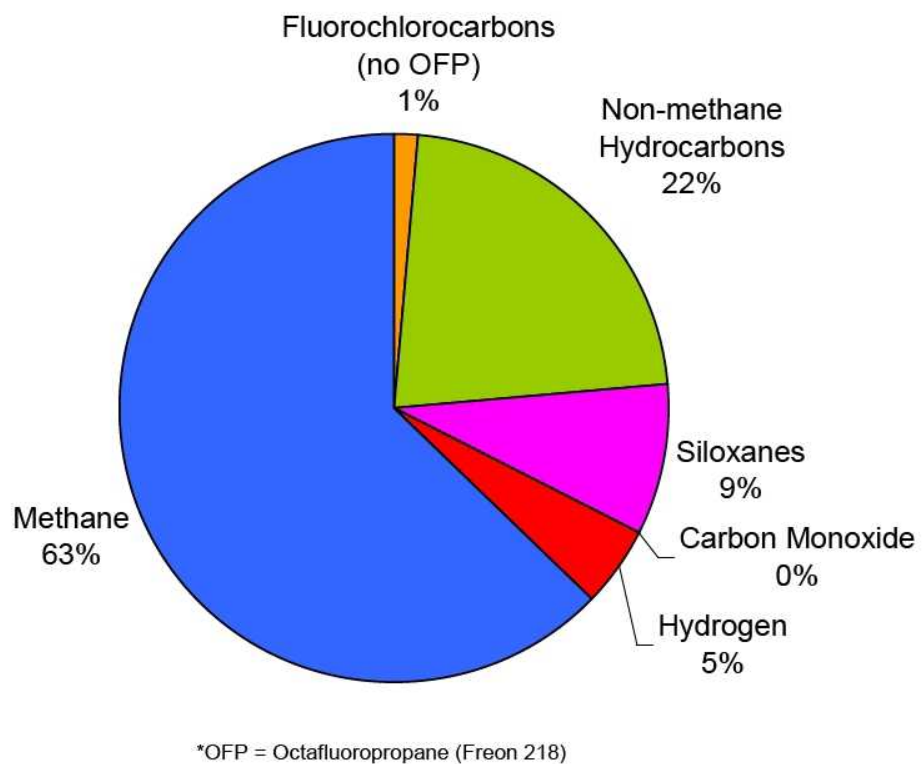

Figure 1. Picture of ISS atmosphere. 


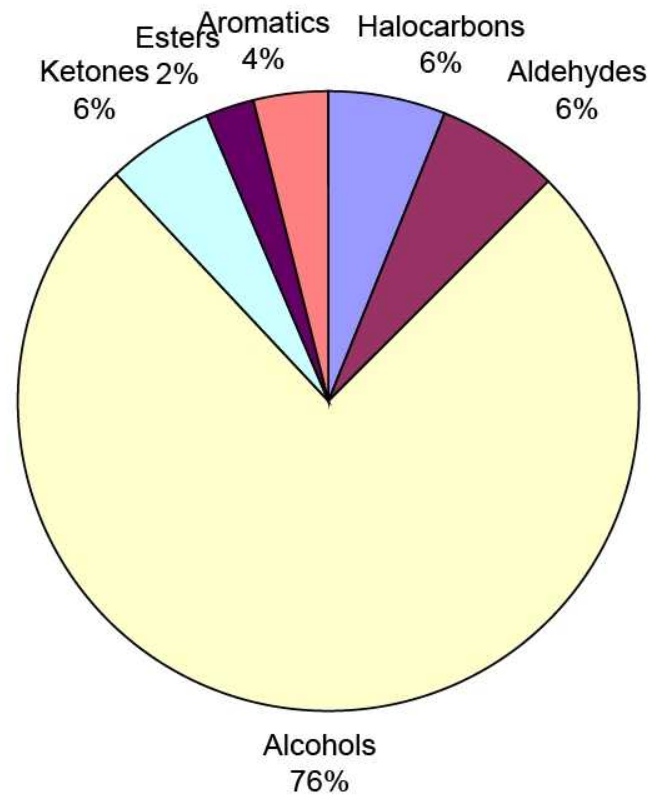

Figure 2. Non-methane volatile organic compounds typically present on ISS.

Trace contaminants found in the ISS atmosphere can be sub-categorized into four different sources - human metabolism, equipment off-gassing, system chemicals, and payload chemicals. Although they are primarily products of human metabolism, methane, hydrogen, and carbon dioxide are listed as major constituents because their higher-than-trace concentration levels observed on ISS. Other products of human metabolism, ammonia, n-butanol, acetaldehyde, methanol, ethanol, etc, are usually present in trace amounts only. This is also true of chemicals from off-gassing. Systems chemicals are the working fluids in the various systems throughout the ISS, for example, octafluoropropane which is used as the working fluid in the interior Russian thermal control system. Ammonia is present as the working fluid of the USOS exterior thermal control system. Although systems are designed for minimum risk, fault tolerant, and can have several layers of containment, leaks can occur as evident in the appearance of system chemicals in archival samples of the ISS atmosphere. Table 1 lists the various chemicals species nominally found in the ISS cabin atmosphere and their average concentration in $\mathrm{mg} / \mathrm{m}^{3}$. 


\begin{tabular}{|l|l|l|}
\hline Halocarbons & $\mathbf{~ m g} / \mathbf{m}^{3}$ & $\mathbf{p p m}$ \\
\hline \hline Dichlorodifluoromethane (Freon 12) & 0.038 & 0.008 \\
\hline Chloromethane (Methyl Chloride) & 0.025 & 0.012 \\
\hline Dichloromethane (Methylene Chloride) & 0.114 & 0.033 \\
\hline 1,1,2-trichloro-1,2,2-trifluoroethane (Freon 113) & 0.030 & 0.004 \\
\hline Octafluoropropane (Perfluoropropane, (Freon 218) & 91.4 & 11.9 \\
\hline Bromotrifluoromethane (Halon 1301) & 0.231 & 0.038 \\
\hline Aldehydes & & \\
\hline \hline Acetaldehyde & 0.317 & 0.176 \\
\hline Propanal & 0.051 & 0.021 \\
\hline Propenal (Acrolein) & 0.018 & 0.008 \\
\hline Butanal (Butyraldehyde) & 0.043 & 0.014 \\
\hline Pentanal & 0.032 & 0.009 \\
\hline Hexanal & 0.036 & 0.009 \\
\hline Heptanal & 0.030 & 0.006 \\
\hline Alcohols & & \\
\hline \hline Methanol & 0.716 & 0.546 \\
\hline Ethanol & 4.056 & 2.15 \\
\hline Isopropanol & 0.391 & 0.159 \\
\hline n-Butanol & 0.175 & 0.058 \\
\hline Ketones & & \\
\hline \hline Acetone & 0.319 & 0.134 \\
\hline 2-Butanone (Methyl Ethyl Ketone) & 0.062 & 0.021 \\
\hline Cyclohexanone & 0.049 & 0.012 \\
\hline Esters & & \\
\hline \hline Ethyl acetate & 0.110 & 0.031 \\
\hline Butyl acetate & 0.034 & 0.007 \\
\hline Aromatic & & \\
\hline \hline Benzene & 0.025 & 0.008 \\
\hline Toluene & 0.075 & 0.020 \\
\hline m-Xylene/p-Xylene & 0.060 & 0.014 \\
\hline o-Xylene & 0.106 & 0.025 \\
\hline Siloxanes & & \\
\hline \hline Octamethylcyclotetrasiloxane & 1.097 & 0.090 \\
\hline Decamethylcyclopentasiloxane & 0.389 & 0.026 \\
\hline Hexamethylcyclotrisiloxane & 1.439 & 0.158 \\
\hline \hline Methane & 14.5 & 22.0 \\
\hline Hydrogen & 1.64 & 19.8 \\
\hline Carbon Monoxide & 0.526 & 0.459 \\
\hline & & \\
\hline
\end{tabular}


Table 1. Chemicals nominally found in the ISS atmosphere. The average concentration of each compounds in $\mathrm{mg} / \mathrm{m}^{3}$ are listed next to each compound. Concentration data for these compounds were collected from December 1998 to August 2009 by archival sampling. Average concentration for octafluoropropane excludes off-nominal concentrations from 2001-2002, but does include the release that occurred in May 2008.

Bromotrifluoromethane (Halon 1301) is the fire suppressant agent used in the U.S. Shuttle. However, because of leaks in the portable fire extinguishers on the Shuttle and subsequent migration into the ISS atmosphere during docked operations, Halon 1301 can be seen in ISS cabin air samples. Siloxanes and aromatics can be linked to off gassing of lubricants, seals, adhesives, paints, and coating used in hardware. Esters can be linked to crew metabolism and hardware off gassing. However, since esters are common solvents, the greater source is most likely the latter of the two. The average NMVOC concentration on ISS from December 1998 to August 2009 is approximately $11.8 \mathrm{mg} / \mathrm{m}^{3}$. An increase in NNVOCs was observed in Increments 16 and 17 during
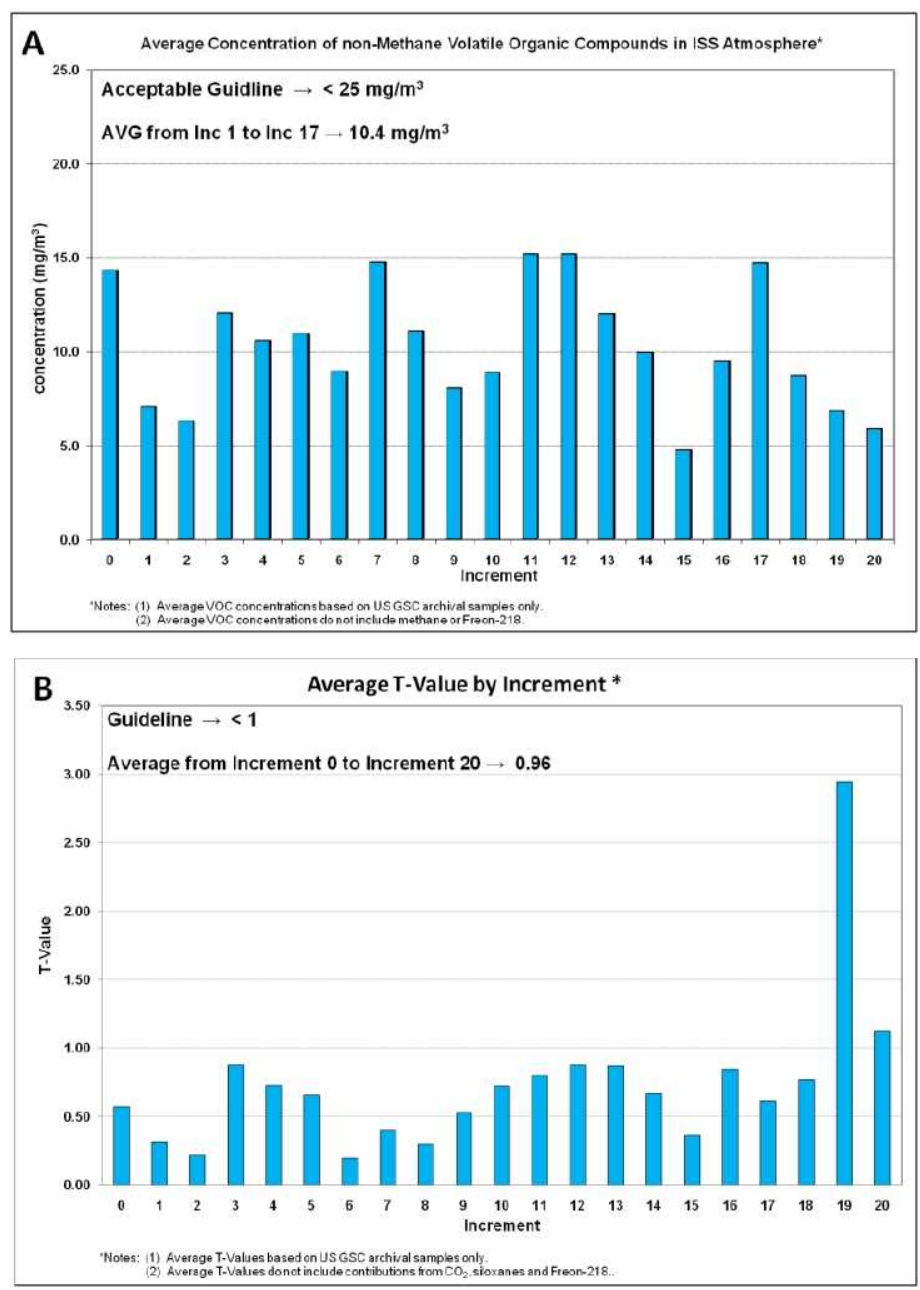

Figure 3A and 3B. A) Average nMVOC concentration in ISS, B) average t-Value in ISS. which Node 2, Columbus, and Japanese modules were added. Although an increase in material off-gassing is expected with the addition of these modules, it should be noted that this increase is accompanied with an increase in the overall volume of ISS. It appears that as the modules age, the amount of offgassing products emitted likely decreases. Starting in Increment 18, the levels of NMVOCs decrease which could be a reflection of decreased amounts of off-gas products and a greater distribution throughout the ISS volume. (Figure 3)

Levels of non-methane VOCs and T-values on ISS since Expedition 0 have been well below the acceptable levels set in the MORD. Expedition 19 and 20 did show a higher than normal Tvalue because of the presence of 
acrolein in the GSC samples returned. Acrolein (propenal) has a very low SMAC and very low concentrations will result in higher than normal T-values for that time period.

\section{Microbial Sources of Atmospheric Contaminants}

Microbial Volatile Organic Compounds (MVOCs) are composed of low molecular weight alcohols, aldehydes, amines, ketones, terpenes, aromatic and chlorinated hydrocarbons, and sulfur-based compounds, all of which are variations of carbon-based molecules. Some MVOC's have a very low odor threshold making them easily detectable by smell. They often have strong odors and are responsible for descriptions such as "old cheese", "dirty socks" or "locker room" smells associated with mold and bacterial growth. (Pasanen, et al, 1998)

MVOCs are products of the microbes' primary and secondary metabolism. In primary metabolism, the organism breaks down food in the environment to extract nutrients needed for the maintenance of cell structures and, in the process, creates MVOC's as by-products. In secondary metabolism, the production of MVOCs is driven by the competition for resources in a nutrient-poor environment. MVOCs produced during primary fungal metabolism include ethanol, 1-octen-3-ol, 2-octen-1-ol, and benzyl cyanide. Some fungi can produce ethanol by fermentation. Others, such as Aspergillus niger, Aspergillus flavus, and Penicillium roqueforti are able to produce 1-octen-3-ol. Low concentrations of this particular MVOC emit a mushroom-like or musty odor. Aspergillus flavus can also produce 2-octen-1-ol which has been described as "a strong musty, oily odor". The fungus Botrytis cinerea can produce benzyl cyanide which emits a grassy odor.(Wesson, et al, 1996) (Korpe, et al, 1998)

MVOCs produced during fungal secondary metabolism include 2-methyl-isoborneol, geosmin (1-10-dimethyl-trans-9-decalol), and terpenes. Chaetomium sp. is known produce 2-methyl isoborneol and geosmin emitting a musty, earthy odor. Penicillium aurantiogriseum and Penicillium vulpinum growing on oat substrate have been shown to produce terpenes. The greatest occurrence of MVOC production (especially terpenes and sesquiterpenes) seems to coincide with spore formation and mycotoxin production as observed in species of Aspergillus and Penicillium. Mycotoxins differ from MVOC's in that they are relatively large molecules that are not volatile, and do not easily evaporate or "off-gas" into the air. Information on bacterial MVOC's produced in indoor settings is limited. Studies conducted on a few bacteria, such as the actinomycetes Streptomyces griseus and Streptomyces odorifer show that they can produce geosmin, 2-methyl isoborneol, and 3-methyl-butanol.(Polizzi, et al, 2009) (Claeson, et al, 2009) (Wolkoff, et al, 2001)

MVOCs are relevant in the indoor setting for several reasons. First, the perception of MVOC's is an indication that microbial growth is occurring. Their potential to elicit health effects remains speculative. Fungi and bacteria may survive or dominate by producing toxic chemicals, such as mycotoxins and MVOC's, to inhibit or kill their 
competitors. These chemicals, at the concentrations that occur at the microbial/microbial interface, can interfere with cellular processes such as DNA, RNA, and protein synthesis and membrane or enzyme functions. Extrapolating these effects to plants or animals involves a consideration of cellular resistance (or sensitivity) and dose. In the indoor environment, exposure to fungal MVOC's has been blamed for headaches, nasal irritation, dizziness, fatigue, and nausea. However, evidence is inconclusive on this point, and other factors should also be considered. A few studies have attempted to document the effects of direct exposure to MVOC's, but none have unequivocally documented a connection with any health effect at any concentration commonly measured in contaminated buildings. Although a few studies have implied a causal relationship between exposure and symptoms of disease, there are still aspects of this relationship that need to be evaluated. The specific toxic properties and concentrations of MVOC's needed to produce symptoms are still unknown.(Thrasher, et al, 2009)

Researchers are particularly interested in determining whether the presence of "marker" chemicals, such as MVOC's, could equate to building contamination. Comparative analysis of MVOC levels from outdoor, indoor affected, and indoor unaffected areas may provide information on microbial contamination in buildings. Studies comparing the level of VOC's in indoor air and MVOC emissions from microorganisms in culture have been performed. Pasanen, at al (1998) determined the levels of 27 VOCs in three identical rooms under sterile conditions and with microbial growth in various locations in the test rooms. The differences between the levels of VOCS in the room under the two conditions were essentially negligible.

\begin{tabular}{|c|c|c|c|c|c|c|}
\hline & \multicolumn{2}{|c|}{ Room 1 } & \multicolumn{2}{c|}{ Room 2 } & \multicolumn{2}{c|}{ Room 3 } \\
\hline & Microbial & Sterile & Microbial & Sterile & Microbial & Sterile \\
\hline $\begin{array}{c}\Sigma \text { VOCs } \\
\left(\mathbf{n g} / \mathbf{m}^{\mathbf{3}}\right)\end{array}$ & 6871 & 6905 & 119,832 & 120,407 & 4320 & 4306 \\
\hline
\end{tabular}

Table 2. Sum of VOCs detected in test rooms.

Generally, volatile organic compounds can be attributed mainly to the off-gassing of materials.(Stutte, et al, 1997) Intuitively, this makes sense since on a per mass basis, there is more material on ISS than human crew. Extending this even further, one would expect the contribution of MVOCs to the overall volatile organic load to be much smaller than the contribution of the crew. However, microbial growth can produce variable MVOC's depending on the substrate and the phase of microbial growth. MVOC's emitted by microbes in the field may also differ from those in lab cultures because the competition for resources that occurred in the investigated area is difficult to reproduce in the laboratory setting. Moreover, some VOC's may be from non-microbial sources, or anthropogenic sources, such as limonene and pinene in cleaning agents. Another issue in the determination of MVOCs is the detection limit of the analytical method employed in the quantitative determination of MVOCs. MVOCs mixtures are quite complex with 
typical concentration levels of MVOCs in the parts per billion to sub-parts per billion range. (Udhe, et al, 2007) The analytical techniques used to analyze ISS cabin atmosphere samples collected by GSCs can confidently detect VOCs at concentrations of $0.05 \mathrm{mg} / \mathrm{m}^{3}$ or higher. Limited analytical success appears to have been achieved with highly sophisticated techniques such as liquid chromatography coupled to tandem mass spectrometry or with newly developed techniques such as selective ion flow tube mass spectrometry.(Scotter, et al, 2005) Despite the continued work on the identification of MVOCs, whether or not contributions from the laboratory atmosphere in which the analyses are performed exist in the final results remains to be sufficiently answered. Generally, microbial contamination exists in conjunction with human presence and these analyses are virtually impossible to perform in a completely sterile environment.
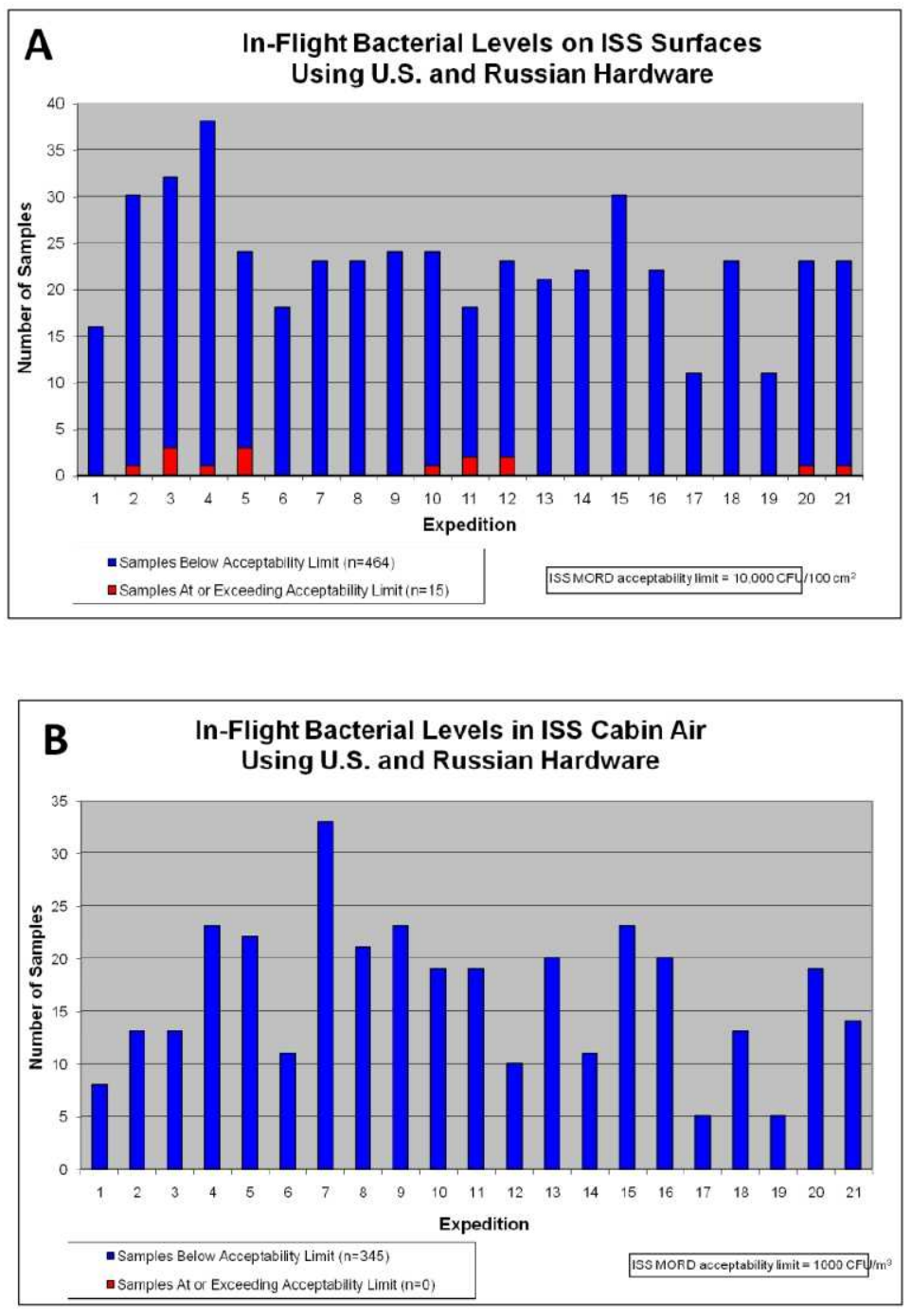

Figure 4A and 4B. Surface and air bacterial levels on ISS by expedition.
With all these considerations in mind, more studies are needed to further current knowledge of MVOC's and their effects on human health.

Microbial surveillance on board the International Space Station (ISS) began in December of 2000 with arrival of the first permanent crewmembers in order to minimize the risk of infection to crew and mitigate potential contamination that might adversely affect the spacecraft environment and systems operation. Monitoring encompasses measurements of the bacterial and fungal loads on both exposed surfaces and cabin air of the habitable volume of the ISS. Environmental samples are collected in accordance with the Medical Operations Requirements Document for International Space Station

(ISS MORD), which defines specific acceptable levels, or better defined as alert levels that indicate adverse events may be impending, for the microbial load on surfaces and 
in the air. Collection and on-board analysis of in-flight samples is accomplished using NASA's Surface Sampler Kit (SSK) and the Microbial Air Sampler (MAS) Kit and collection of samples for ground-based analysis using the Russian Sample Tube Kit and Ecosphere air sampling device (see Figures 4 and 5 . The most common bacterial species isolated from ISS samples are Staphylocococcus and Bacillus. The most common fungal species isolated from ISS samples are Aspergillus and Penicillium.

While ISS crewmembers have not reported any overwhelming incidences of musty odors on the ISS, there have been some events where microbial growth, detected by either monitoring techniques or visual observation, may have contributed to the VOC content of the ISS environment. These events, as well as the corrective actions taken to eliminate the contamination, are described below.
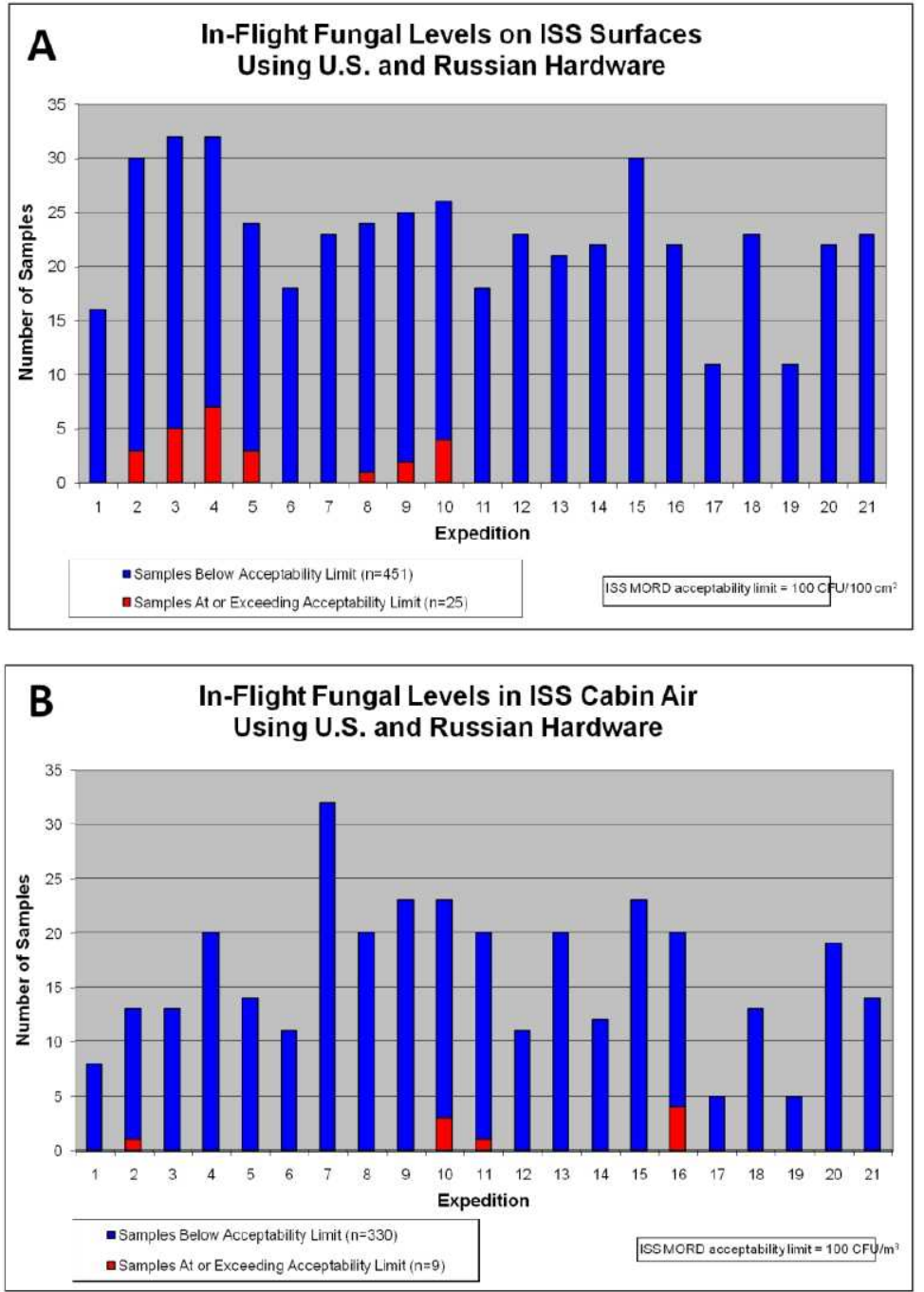

Figure 5A and 5B. Surface and air fungal levels on ISS by expedition.
December 2000 - November 2009

During nominal monitoring activities, results have indicated occasional surface bacterial and fungal contamination levels above ISS MORD acceptability limits (bacterial limit $=10,000$ colony forming units $/ 100 \mathrm{~cm}^{2}$; fungal limit $=100$ colony forming units/100 $\mathrm{cm}^{2}$ ). In each incident when increased levels of contamination were determined, remediation was performed using housekeeping disinfectant wipes.

December 2000 - November 2009

During nominal monitoring activities, results have indicated occasional air fungal contamination levels above ISS MORD acceptability limits (bacterial limit $=1,000$ colony forming units $/ \mathrm{m}^{3}$; fungal limit $=100$ colony forming units/ $\mathrm{m}^{3}$ ). The ISS cabin air is purified by use of HEPA filtration in the U.S. portion of ISS or by use of the Potok air purification device in the Russian portion of the ISS. 


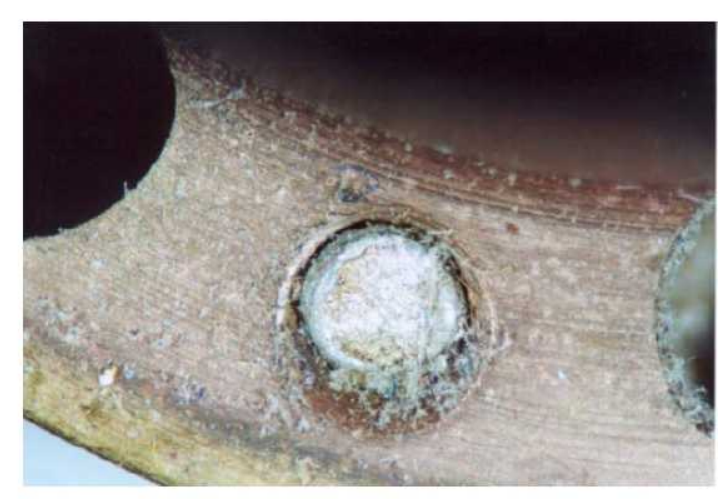

Figure 6. Fungal contaminated Russian smoke detector.

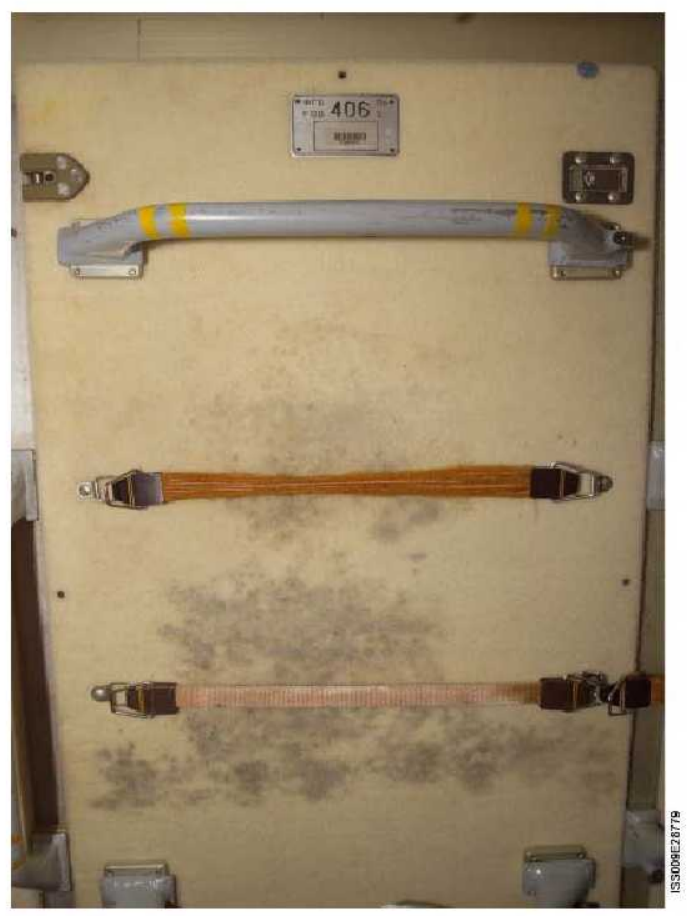

Figure 7. Fabric panel in FGB potentially contamination with fungus.

2001

A Russian smoke detector failed. Upon investigation of the failure after the unit was returned to Earth, fungal contamination was determined to be the primary cause due to biodegradation of the electrical components. (Figure 6)

\section{November 2004}

Potential fungal contamination on FGB (Russian Functional Cargo Block) fabriccovered panels was reported by an Expedition 9 crewmember. In-flight sampling with the SSK indicated fungal levels at or above the ISS MORD acceptability limit. Investigations into the cause of the contamination indicated that the area in which the panels are located was being used for crew hygiene activities. During these activities, small volumes of free-floating water were being released. In addition, damp garments and towels were being secured behind straps attached to the panels for drying. Repeated remediation was performed using Russian-provided biocidal wipes. Hygiene activities were further defined so that no further release of free-floating water occurred and items were not secured tightly to panels for drying. Initial indication was that these efforts proved successful. However in October 2007, air samples collected in this same area indicated elevated fungal levels. Further remediation was performed and a Potok device was installed in this area and is operated on a daily basis. Fungal levels are remaining below acceptable limits. (Figure 7)

\section{August 2007}

Suspected fungal contamination on a Russian 'BOK-3' Command Processing Unit with some condensation pooling behind panels was reported. No sampling was performed. The unit and area were vacuumed and cleaned with Russian biocidal wipes. It was later determined the suspected contamination was dust and debris. 


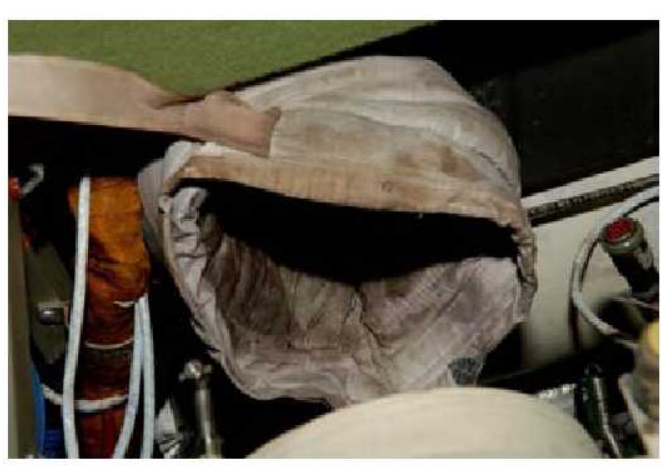

Figure 8. Discolored Russian A/C duct.

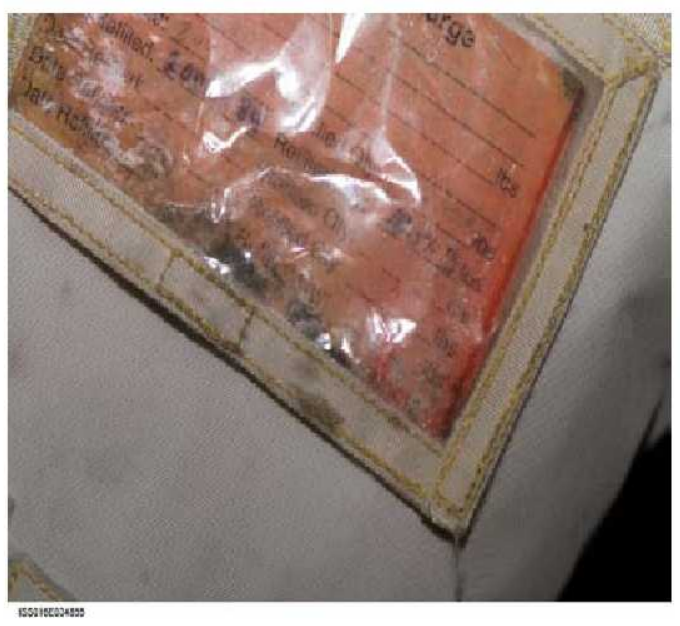

Figure 9. Fungal contamination on US payload water reservoir.

August 2007

Discoloration on Russian A/C ductwork was found. No sampling was performed. The unit and area were vacuumed and cleaned with Russian biocidal wipes. It was later determined the suspected contamination was dust and debris. At the first available opportunity, the ductwork was replaced. (Figure 8)

\section{April 2008}

Fungal contamination was observed on a U.S. leaking Payloads Water Reservoir (PWR). Onorbit decontamination was considered, but was determined to be unnecessary. The PWR was placed into two layers of containment and returned to ground for evaluation and refurbishment. Sampling was performed on the ground to rule out the presence of pathogens in order to protect personnel who would be handling the PWR for refurbishment. (Figure 9)

\section{Conclusions}

The only means to maintain the quality of spacecraft cabin atmospheres is to effectively manage the balance between the generation and removal of volatile trace contaminants. This is accomplished only with a thorough understanding of the dynamics of atmospheric contaminants during various phases of a space mission. Many of the atmospheric contaminants in ISS can be attributed to material off-gassing. Contributions to the overall NMVOC load from crew metabolism accounts for much of the rest. Despite a minor contribution, microbial contributions to ISS air quality should not be discounted. As long as human presence is on-board spacecraft, microbial presence will always be true. However, separating crew metabolic contributions to the NMVOC load from microbial contributions is extremely challenging. Many of the contaminants are very similar to one another since they are from metabolic processes, either human or microbial. However, given the potential impact microbial growth may have on the air quality of ISS, it is certainly worthwhile to ensure that the extent of proliferation of microbial growth be managed 


\section{References}

Claeson, A.-S., Nordin, S., Sunesson, A.-L. Effects on Percieved Air Quality and Symptoms of Exposure to Microbially Produced Metabolites and Compounds Emitted from Damp Building Materials. Indoor Air, 19, pp. 102-112, 2009.

Korpe, A., Pasanen, A-L. Pasanen, P. Volatile Compounds Originating from Mixed Microbial Cultures on Building Materials Under Various Humidity Conditions. App. And Envir. Microbiology, 64(8), pp. 2914-2919, 1998.

Macatangay, A. V., Prokhorov, K. S., Sweterlistch, J. J. Strategies to Mitigate Ammonia Release on the International Space Station. SAE 2007-01-3186. Society for Automotive Engineers. Warrendale, PA, 2007, and references therein.

Macatangay, A. V., Perry, J. L. Cabin Air Quality on Board MIR and the International Space Station - A Comparison. SAE 2007-01-3219. Society for Automotive Engineers. Warrendale, PA, 2007, and references therein.

Pasanen, A.-L., Korpi, A., Kasanen, J.-P., Pasanen, P. Critical Aspects on the Significance of Microbial Volatile Metabolites as Indoor Air Pollutants. Envir. Intl. 24(7), pp. 703-712, 1998.

Perry, J.L., James, J.T., Cole, H.E., Limero, J.T., Beck, S.W. Rational and Methods for Archival Sampling and Analysis of Atmospheric Trace Chemical Contaminants On Board Mir and Recommendations for the International Space Station. NASA TM-108534, NASA Marshall Space Flight Center: Huntsville, AL, 1997.

Perry, J.L. Elements of Spacecraft Cabin Air Quality Control Design. NASA TP-1998207978, NASA Marshall Space Flight Center: Huntsville, AL, 1998.

Polizzi, V., Delmulle, B., Adams, A., Moretti, A., Susca, A., Picco, A.M., Rosseel, Y., Kindt, R., Van Bocxlaer, J., De Kimpe, N., Van Peteghem, C., De Saeger, S. Fungi, Mycotoxinc, and Microbial Volatile Organic Compounds in Mouldy Interiors from Water-Damaged Buildings. J. Envi. Montoring, 11, pp. 1849-1858, 2009.

Schöller, C., Molin, S., Wilkins, K. Volatile Metabolites from Some Gram-Negative Bacteria. Chemosphere, 35(7)pp. 1487-1495, 1997.

Scotter, J.M., Langford, V.S., Wilson, P.F., McEwan, M.J., Chambers, S.T. Real-Time Detection of Common Microbial Volatile Organic Compounds from Medically Important Fungi by Selective Ion Flow Tube-Mass Spectrometry. J. Microbiological Methods, 63, pp. 127-134, 2005.

Stutte, G.W., Wheeler, R.M. Accumulation and Effect of Volatile Organic Compounds in Closed Life Support Systems. Adv. Space Research, 20(10)pp. 1913-11922, 1997. 
Thrasher, J.D., Crawley, S. The Biocontaminants and Complexity of Damp Indoor Spaces: More Than Meets the Eyes. Tox and Industrial Health, 25(9-10)pp. 583-615, 2009.

Uhde, E., Salthammer, T. Impact of Reaction Products from Building Materials and Furnishings on Indoor Air Quality - A Review of Recent Advances in Indoor Chemistry. Atmos. Environment, 41, pp. 3111-3128, 2007.

Wessen, B., Schoeps, K.-O. Microbian Volatile Organic Compounds - What Substances can be Found in Sick Buildings? Analyst. 121, pp. 1203-1205, 1996.

Wolkoff, P., Nielson, G.D. Organic Compounds in Indoor Air - Their Relevance for Percieved Indoor Air Quality. Atm. Environment, 35, pp. 4407-4417, 2001. 